\title{
Review: most selective serotonin reuptake inhibitors lead to adverse events that appear to outweigh the benefits in children
}

Whittington $C J$, Kendall T, Fonagy $P$, et al. Selective serotonin reuptake inhibitors in childhood depression: systematic review of published versus unpublished data. Lancet 2004;363:1341-5.

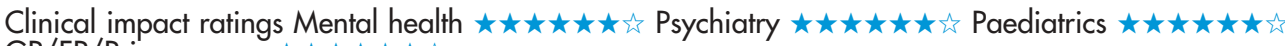

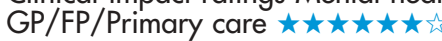

Are selective serotonin reuptake inhibitors (SSRIs) safe and effective for treating depression in children?

\section{METHODS}

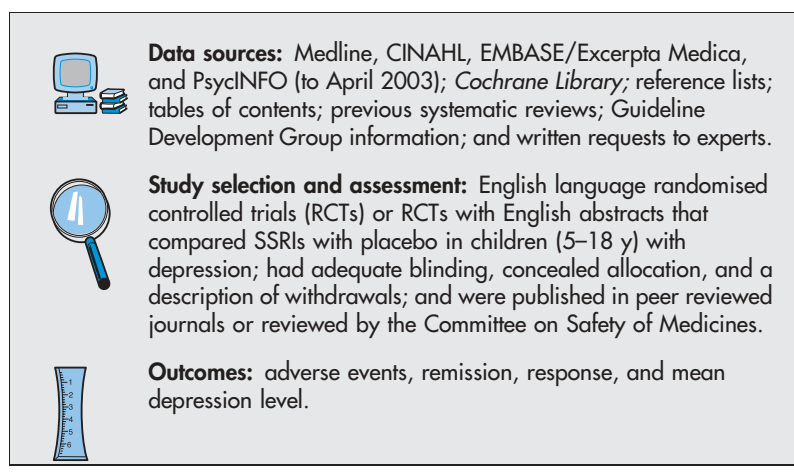

\section{MAIN RESULTS}

6 published and 6 unpublished RCTs were reviewed. Fluoxetine showed a benefit for remission and response, and the adverse event data were not statistically significant (table). Paroxetine increased remission but not response and increased serious adverse events (table). Sertraline did not show a benefit for remission and led to more dropouts because of adverse events (table); a treatment effect for response had borderline significance. Citalopram led to a small reduction in depressive symptoms, and venlafaxine had no effect; adverse events were increased for both drugs (table).

\section{CONCLUSIONS}

In children with depression, fluoxetine improves symptoms without increasing adverse events. For paroxetine, sertraline, venlafaxine, and citalopram, the risks appear to outweigh the benefits.

A modified version of this abstract appears in Evidence-Based Nursing. For correspondence: Dr C Whittington, University College London, London, UK. c.whittington@ucl.ac.uk

Source of funding: no external funding.

\section{Commentary}

W hittington et al have highlighted 3 key issues in the evaluation of the evidence base for antidepressant treatment in children and adolescents: effectiveness, safety, and the role of access to published versus unpublished data. A consistently high placebo response is noted, which emphasises the importance of undertaking controlled clinical trials for antidepressants in young people rather than assuming efficacy based on adult studies. Adverse effects also appear to be higher in children. The authors concluded that except for fluoxetine, the evidence does not support a favourable risk-benefit balance for SSRIs in child and adolescent depression. In addition to including unpublished negative trials, Whittington et al also criticised the interpretation of marginal results to produce apparently positive published studies (eg, sertraline, paroxetine) which, on reanalysis, do not show effectiveness and for which the impact of the risk-benefit ratio has also been ignored. The authors' conclusions are essentially the same as those reached by regulatory agencies that had access to the full data set ${ }^{12}$ and by other authors who have reviewed the published studies. ${ }^{3} 4$ This review illustrates the problem of publication bias in "evidence-biased medicine," ${ }^{\prime 5}$ which includes biased interpretation of published data in favour of the drug and inability to weigh the full body of evidence because of lack of access to unpublished data.

E Jane Garland, MD, FRCPC

University of British Columbia, Vancouver, British Columbia, Canada

1 Medicines and Health Care Products Regulatory Agency. Use of Selective Serotonin Reuptake Inhibitors (SSRIs) in children and adolescents with major depressive disorder (MDD) - only fluoxetine (Prozac) shown to have a favourable balance of risks and benefits for the treatment of MDD in the under 18s, Dec 10, 2003. http://www.mhra.gov.uk/news/2003.htm (accessed 27 Oct 2004)

2 Laughren, T. Background comments for February 2, 2004 Meeting of Psychopharmacological Drugs Advisory Committee (PDAC) and Pediatric Subcommittee of the Anti-Infective Drugs Advisory Committee (Peds AC). http://www.fda.gov/ohrms/dockets/ac/04/briefing/2004-4065bl.htm (accessed 27 Oct 2004)

3 Garland EJ. CMAJ 2004; 170:489-91.

4 Jureidini JN, Doecke CJ, Mansfield PR, et al. BMJ 2004;328:879-83.

5 Melander H, Ahlqvist-Rastad J, Meijer G, et al. BMJ 2003;326:1171-3.

Selective serotonin reuptake inhibitors (SSRIs) $v$ placebo for depression in children*

\begin{tabular}{|c|c|c|c|c|}
\hline SSRI & Outcomes at $\leqslant 12$ weeks (number of studies) & Event rates & $\operatorname{RRR}(95 \% \mathrm{Cl})$ & NNT (Cl) \\
\hline \multirow[t]{4}{*}{ Fluoxetine } & Serious AE (1) & $0.9 \% \vee 3.6 \%$ & $75 \%(-122$ to 97$)$ & NS \\
\hline & & & Weighted RRI (CI) & NNH (Cl) \\
\hline & Suicide attempt (1)† & $2.4 \% \vee 1.9 \%$ & $26 \%(-64$ to 340$)$ & NS \\
\hline & Discontinuation (2)‡ & $5.7 \%$ v $6.3 \%$ & $19 \%(-82$ to 685$)$ & NS \\
\hline \multirow[t]{3}{*}{ Paroxetine } & Serious AE (2) & $12 \% \vee 4.4 \%$ & $155 \%$ (23 to 430$)$ & 15 (8 to 50$)$ \\
\hline & Suicide attempt/ideation (2) & $3.7 \%$ v $2.5 \%$ & $51 \%(-38$ to 269$)$ & NS \\
\hline & Discontinuation (1) & $9.7 \% \vee 6.9 \%$ & $40 \%(-48$ to 278$)$ & NS \\
\hline \multirow[t]{3}{*}{ Sertraline } & Serious AE (2) & $3.7 \%$ v $3.3 \%$ & $14 \%(-61$ to 232$)$ & NS \\
\hline & Suicide attempt/ideation (2) & $2.6 \% \vee 1.1 \%$ & $143 \%(-52$ to 1139$)$ & NS \\
\hline & Discontinuation (2) & $9.0 \% \vee 2.7 \%$ & $236 \%$ (27 to 793 ) & $17(9$ to 50$) \S$ \\
\hline \multirow[t]{3}{*}{ Citalopram } & Suicide attempt (2) & $7.1 \%$ v $3.6 \%$ & $99 \%(-17$ to 377$)$ & NS \\
\hline & Treatment emergent $A E(2)$ & $79 \%$ v $70 \%$ & $13 \%$ (1 to 27$)$ & 12 (6 to 100$)$ \\
\hline & Discontinuation (2) & $8.6 \% \vee 7.1 \%$ & $20 \%(-38$ to 135$)$ & NS \\
\hline \multirow[t]{2}{*}{ Venlafaxine } & Suicide related events (2) & $7.7 \% \vee 0.6 \%$ & $1277 \%$ (83 to 10261$)$ & $15(10$ to 34$)$ \\
\hline & Discontinuation (2) & $10 \%$ v $3.0 \%$ & $246 \%$ (30 to 821$)$ & $15(9$ to 50$)$ \\
\hline
\end{tabular}

${ }^{*} \mathrm{AE}=$ adverse events; NS = not significant. Other abbreviations defined in glossary. †lncludes unpublished data. ¥Studies combined using random effects model; fixed effects model used for all others. §Data supplied by author. 'Serotonin and noradrenaline reuptake inhibitor. 